\title{
La objeción de conciencia como eximente de la responsabilidad penal en colombia ${ }^{1}$ \\ Conscientious objection as an exempt of criminal responsability in Colombia
}

Fecha de recepción: 06/03/2018 - Fecha de aceptación: 09/04/2018

Ricardo Posada-Maya²

\section{Resumen}

La objeción de conciencia es uno de los temas más estudiados en la literatura constitucional extranjera en los últimos años que, sin embargo, en nuestro medio es casi inexistente. En Colombia tampoco se ha analizado a profundidad su posible tratamiento como una causal de ausencia de responsabilidad innominada en el CP de 2000. El presente texto académico tiene como propósito verificar la posibilidad de aplicar la objeción de conciencia, bien como una causal de atipicidad o como una causal de inculpabilidad (por falta de exigibilidad), y determinar sus características y elementos dogmáticos particulares a la luz de la doctrina nacional e internacional y de la jurisprudencia de la Corte Constitucional, que la ha reconocido en múltiples ámbitos vitales como, por ejemplo, en el aborto lícito, las prácticas sanitarias, la educación y el servicio militar obligatorio, entre otras actividades sociales.

1 Profesor del Área de Derecho Penal, Procesal Penal y Criminología. Director del Grupo de Estudios e Investigación en Derecho Penal y Justicia Transicional "Cesare Beccaria" de la Universidad de Los Andes, Bogotá-Colombia. Doctor en Derecho por la Universidad de Salamanca, España. Conjuez de la Sala Penal de la Corte Suprema de Justicia de Colombia. El presente artículo se inscribe en la línea de aspectos fundamentales del derecho penal sustantivo y procesal penal del Grupo de Investigaciones en Derecho Penal y Justicia Transicional "Cesare Beccaria" de la Universidad de Los Andes, Colombia.

2 Ponencia realizada en el I Congreso Internacional de Derecho Penal, Homenaje al Prof. Dr. Dr. hc. mult. Claus Roxin, Bogotá, Universidad Libre, 15, 16 y 17 de marzo de 2017 


\section{Palabras clave}

Culpabilidad, objeción de conciencia, libertad de conciencia, ejercicio de derechos, exigibilidad penal, causales de inculpabilidad.

\section{Abstract}

Conscientious objection is one of the most studied topics in the foreign constitutional literature in recent years, which, however, in our environment is almost non-existent. In Colombia, it has not been analyzed in depth its possible treatment as a cause of absence of innominate responsibility in the CP of 2000. The purpose of this academic text is to verify the possibility of applying conscientious objection, either as a cause of atypicality or as a cause of inculpability (for lack of enforceability), and determine its particular characteristics and dogmatic elements in the light of national and international doctrine and the jurisprudence of the Constitutional Court, which has recognized it in many vital areas, such as, for example, in licit abortion, health practices, education and compulsory military service, among other social activities.

\section{Keywords}

Culpability, conscientious objection, freedom of conscience, excercise of rights, criminal enforcement, causals inculpability.

\section{Sumario}

1. Consideraciones generales. 2. Culpabilidad como capacidad de motivabilidad, el derecho a la conciencia y la objeción de conciencia. 3. La conciencia en el marco legal de la teoría del delito colombiana. Elementos y requisitos de la objeción de conciencia. 4. Conclusiones. 5. Bibliografía. 


\section{Consideraciones generales}

"En el juicio práctico de la conciencia, se expresa la relación de la libertad con la verdad ${ }^{3 \prime}$.

REVELLO

Uno de los temas menos estudiados por la doctrina y la jurisprudencia colombiana es el relativo al derecho a las objeciones de conciencia ${ }^{4}$, y en particular su influencia jurídica en la determinación de la responsabilidad penal de quienes han realizado omisiones punibles motivadas por principios, ideas o convicciones personales. El panorama es desolador, la doctrina penal nacional es exigua en el tema, la Corte Suprema de Justicia (Sala Penal) si acaso se ha ocupado de la objeción de conciencia del testigo para prestar juramento y los efectos de este en el valor del testimonio ${ }^{5}$, mientras que la Corte Constitucional ha abordado esta institución en cuestiones muy diversas e interesantes como el aborto, el ejercicio de deberes constitucionales y el servicio militar obligatorio, la imparcialidad judicial, el ejercicio profesional, la salud, educación o el régimen de bancadas de los partidos políticos $^{6}$, mas no lo ha hecho desde la perspectiva de las causales de exclusión de la responsabilidad penal y en particular de las causales de inculpabilidad en los delitos omisivos, con base en el CP, artículos 9, 25 y 32.

3 Revello, Ruben, "La objeción de conciencia en los documentos internacionales", p. 25.

4 Llano Escobar, Alfonso. Acerca del concepto de conciencia, v. Objeción de conciencia institucional, pp. 84 y ss. Y en la p. 88, señala que "La función principal de la conciencia individual, en forma esquemática, es emitir un juicio moral con respecto a la conducta humana, concretamente, con respecto a la acción que va a hacer el sujeto, para lo cual necesita de una escala de valores, presidida por un valor, en cierto sentido, absoluto, que ordena jerárquicamente los demás valores". Utiliza el término objeciones por oposición a una única objeción: Navarro-Valls, Rafael/Martínez Torrón, Javier, Conflictos entre conciencia y ley, pp. 29 y ss. Sobre el concepto de Conciencia: Jericó OJer, Leticia, El conflicto de conciencia ante el derecho penal, pp. 45 y ss. Respecto al concepto de tolerancia: LAFFITte, JEAn. "historia de la objeción de conciencia y diferentes acepciones del concepto de tolerancia", p. 82 y ss. Acerca de la fundamentación antropológica de la objeción de conciencia: v. LUKAE dE STIER, MaRIA LIIIANA, "Objeción de conciencia y antropología", pp. 112 y ss. Sobre la objeción de conciencia y sus fundamentos en el derecho: Morelu, "La objeción de conciencia en el derecho", pp. 41 y ss.

5 C.S.J., SP, Sentencia Rad. 15699 del 27/02/2003, M.P.: Á. Pérez Pinzón.

6 En una línea jurisprudencial que se mantiene, la Corte Constitucional ha abordado el estudio de los siguientes temas: 1) aborto y salud: T-411 de 1994, T-744 de 1996, T-659 de 2002, C-355 de 2006, T-209 de 2008, T-388 de 2009, Auto 327 de 2010; 2) Servicio Militar obligatorio: T-409 de 1992, C-511 de 1994, C-561 de 1995, T-363 de 1995, C-740 de 2001, T-355 de 2002, T-332 de 2004, C-728 de 2009, T-455 de 2014 y SU-108 de 2016; 3) Ejercicio de ciertas profesiones: T-982 de 2001, T-332 de 2004, C-274 de 2016 y Auto 327 de 2010; 4) imparcialidad judicial: C-338 de 2016; 5) juramento: T-547 de 1993, C-616 de 1997; 6) Régimen de Bancadas: C-859 de 2003; y 7) educación: T-539 de 1993, T-075 de 1995, T-588 de 1998, T-877 de 1999, T-026 de 2005. 
Dicho esto, el presente texto explora la institución de la 'objeción de conciencia' y sus efectos en el derecho penal colombiano. En el segundo aparte se caracteriza esta figura en el marco de la noción de la culpabilidad en el CP de 2000. En el tercero, se exploran los diversos efectos que puede tener la objeción de conciencia en la teoría del delito colombiana. En dicho acápite también se precisan los elementos y requisitos de la objeción de conciencia, a partir de las elaboraciones teóricas propuestas por la doctrina penal nacional y la jurisprudencia de la Corte Constitucional. Finalmente, se presentan algunas consideraciones a título de conclusión y la bibliografía.

\section{El derecho fundamental a la conciencia, capacidad de motivabilidad y objeción de conciencia}

1. El artículo 18 de la Constitución prevé la libertad de conciencia como una garantía y un derecho constitucional fundamental ${ }^{7}$, derivada de la libertad en general y de la autonomía de los ciudadanos en particular ${ }^{8}$. Al respecto, se ha dicho que "la libertad, como derecho humano, parte de concebir a las personas como individuos que, en principio, gozan de la facultad de elegir, de tener un sentido propio de justicia, de decidir sobre lo que es bueno o malo para ellos y de poder, en consecuencia, elaborar sus propios planes de vida"'.

Agrega la Constitución que "nadie será molestado por razón de sus convicciones o creencias, ni tampoco podrá ser compelido a revelarlas ni obligado a actuar contra su conciencia". No obstante, y esto es relevante, no se trata de un derecho fundamental absoluto sino relativo, que se divide en varias instituciones y garantías que deben distinguirse, adecuadamente ${ }^{10}$, de la siguiente manera:

En primer lugar, la norma superior consagra la libertad de conciencia como una garantía positiva de libertad ${ }^{11}$, que expresa un derecho fundamental permanente, de

7 Convención Americana sobre Derechos Humanos, artículo 12. En otras convenciones internacionales, v. Pacto Internacional de Derechos Civiles y Políticos, artículo 18; Resolución 77 del 22/04/1998, la Comisión de Derechos Humanos de las Naciones Unidas. Londoño Lazaro, María Carmelina "La protección internacional de la objeción de conciencia: Análisis comparado entre sistemas de derechos humanos y perspectivas en el sistema interamericano", pp. 235 y ss.; Navarro-Valls, Rafael /Martínez Torrón, Javier, Conflictos entre conciencia y ley, pp. 48 y ss.

8 Castrelón Pérez, Mariana "La objeción de conciencia al servicio militar en Colombia: Análisis de la Sentencia C-728 de 2009 y de sus defectos frente a los objetores de conciencia", p. 17. Corte Constitucional, Sentencia C-274 de 2016.

9 Ángel Cabo, Natalia. "El concepto de libertad y el libre desarrollo de la personalidad", pp. 241 y 242.

10 Corte Constitucional, Sentencia SU-108 de 2016.

11 Ángel Cabo, Natalia. "El concepto de libertad libre desarrollo de la personalidad", pp. 242 y ss. 
inmediato cumplimiento, un principio y un valor democrático. La Corte Constitucional en la sentencia C-728 de 2009, precisa que "[... a partir del inalienable fuero interno de cada individuo, éste goza de la facultad para actuar o abstenerse de hacerlo en virtud de su razón práctica, de su pensamiento y de su íntima convicción, claro está, sobre la base, implícita en todo derecho y en toda libertad, de que sus expresiones están limitadas por los derechos de los demás y por las necesidades propias del orden público, la tranquilidad, la salubridad y la seguridad colectivas"12 (cursivas por fuera del texto original).

Asimismo, la Sentencia C-274 de 2016 agrega que:

La consagración de la objeción de conciencia como derecho fundamental está íntimamente relacionada con el carácter democrático pluralista del modelo político y con el reconocimiento de la necesidad de dar cuando entra en tensión la personal valoración ética de una acción humana, con imperativos normativos que amparan derechos de terceros o el bien común, pues como lo ha destacado la jurisprudencia de esta corte "así como los derechos no tienen carácter absoluto, tampoco lo tienen los deberes, so pena de transmutar el listado en uno de índole autoritario y por lo mismo contrario a la vigencia de las libertades individuales" (T-455 de 2014).

En segundo lugar, se prevé una reserva constitucional: Nadie será molestado, impelido, coaccionado o perseguido por razón de sus convicciones o creencias $^{13}$. En un sentido negativo de libertad, la Constitución ha dispuesto la protección frente a las intromisiones indebidas por motivos relacionados con los parámetros vitales más arraigados del ser humano: su esencia espiritual, política y social. Por lo tanto, no cabe duda que esta prohibición constitucional está íntimamente emparentada con otros dos derechos fundamentales: La dignidad humana, bajo el entendido que el ser humano puede vivir como quiera, vivir bien y vivir sin humillaciones (C.N., artículo 1; C.P., artículo 1; Sentencia T-881 de 2002); y con el libre desarrollo de la personalidad (C.N., artículo 16), de los cuales hace parte la conciencia y los valores propios del ser humano.

En el sentir de la doctrina mayoritaria, actuar lícitamente conforme a las convicciones y creencias constituye el ejercicio legítimo de un derecho constitucional que, en principio, no podría constituir un ilícito penal (C.P., artículo 9), pues tales

12 Aunque inicialmente fue negada por la Sentencia T-409 de 1992.

13 Según la RAE, las convicciones son “Del lat. Convictio, - - nis. 1. f. convencimiento. 2. f. Idea religiosa, ética o política a la que se está fuertemente adherido. U.m. en pl.". Por su parte, la creencia se define como: "De creer. 1. f. Firme asentimiento y conformidad con algo. 2. f. Completo crédito que se presta a un hecho o noticia como seguros o ciertos. 3. f. Religión, doctrina". 
comportamientos no solo no comportarían la creación de un riesgo jurídicamente desaprobado en los términos de la actual teoría de la imputación objetiva, sino que, incluso, en caso de colisión de deberes, estas situaciones podrían dar lugar a aplicar una causal de justificación como el ejercicio lícito de derechos (C.P., artículo 32, numeral 5).

En tercer lugar, la Constitución también garantiza el derecho a no revelar las convicciones o las creencias de cualquier naturaleza, como las políticas, las filosóficas y las religiosas. El secreto personal de la conciencia es un pilar inamovible de la libertad personal, de la privacidad y de la dignidad humana en un Estado social y democrático de derecho. En esta línea, por ejemplo, la C.S.J. ha abordado los derechos que tienen los testigos en los procesos penales para abstenerse de revelar sus propias convicciones. También en este ámbito, puede cobrar explicación alguna modalidad del secreto profesional religioso.

Finalmente, en cuarto lugar, la Carta prevé que nadie será obligado a actuar en contra de su conciencia. De acuerdo con la norma, se trata de la garantía de objeción de conciencia, que se inscribe como parte del núcleo duro del derecho a la libertad personal ${ }^{14}$. En igual sentido, la sentencia C-274 de 2016 sostiene que:

En esta cláusula se inscribe el derecho a la objeción de conciencia como una legítima expresión de la libertad humana de dirigir en forma autónoma su propia racionalidad, sin otro límite que la eficacia de los derechos de terceros y el bien común. Es una garantía que reconoce y reafirma que el ser humano, en tanto ser de elecciones, está ontológicamente facultado para aceptar o rehusar, pero que recuerda, asimismo, que "la Constitución impone deberes en consideración a intereses generales de la comunidad y que responden al criterio conforme al cual todas las personas están obligadas a contribuir al mantenimiento de las condiciones que permiten la armónica convivencia" (Sent. C-728 de 2009). (Subrayado por fuera del texto original).

De otro lado, este derecho subjetivo ha sido reconocido ampliamente por la Corte Constitucional a partir de la sentencia hito C-728 de 2009, en la que se trató ampliamente la cuestión de la objeción de conciencia respecto a la prestación del servicio militar obligatorio en Colombia ${ }^{15}$. Ello, al margen de otras providencias

14 Corte Constitucional, Sentencia C-728 de 2009.

15 Constitución Política, artículo 216: “Todos los colombianos están obligados a tomar las armas cuando las necesidades públicas lo exijan para defender la independencia nacional y las instituciones públicas. La ley determinará las condiciones que en todo tiempo eximen del servicio militar y las prerrogativas por la prestación del mismo". Sobre el tema, v. Ángel Ordaz, Carlos. "Non violencia, Objeción de conciencia e insumisión en España, 1970-1990", pp. 2 y ss.; Cohn, Marjorie, /Gilberd, Kathleen, Rules of disengagement, pp. 23 y ss.; Heval Çinar/Üstercí, Conscientious objection, pp. I y 
posteriores que han reconocido este derecho en ámbitos distintos, como sucede en el caso paradigmático de los abortos lícitos, de acuerdo con la Sentencia C-355 de 2006 de la misma corporación.

Está claro, por lo que acaba de decirse, que el tema admite dos variantes. En cuanto a la primera, se advierte el derecho de las personas a actuar conforme a su conciencia ética, política o religiosa, sin que por ello sea permitido castigarlas por realizar comportamientos que no afectan gravemente los derechos o los bienes jurídicos de terceros. De este modo, surge el derecho constitucional a actuar en conciencia, en libertad, de acuerdo con el plan de vida y las propias convicciones, creencias o doctrinas; lo que da lugar a la problemática de los delincuentes por convicción; es decir, de aquellos sujetos que consideran correcta su actuación positiva en el marco de la ley, con el propósito de conseguir ciertos fines ${ }^{16}$. En el ámbito del derecho penal, esta circunstancia está relacionada, por una parte, con la imposibilidad teórica de configurar prohibiciones penales basadas en la conciencia, castigar los delitos de opinión e incluso sancionar los pensamientos, que en la práctica resultan expresiones de un aborrecible derecho penal de autor; y, por la otra, con la posibilidad de excluir determinados injustos penales.

$Y$, en cuanto a la segunda, se advierte la orden constitucional de reconocer, en ciertas circunstancias subjetivas, la imposibilidad de castigar penalmente la omisión jurídica de mandatos constitucionales o legales, incluso en las hipótesis en las que el sujeto tiene el deber de garantizar la indemnidad de bienes jurídicos o de proteger ciertas fuentes de peligro (deber de garante, C.P., artículo 25); justamente, por razones basadas en la prevalencia constitucional de la conciencia ética, política, moral o religiosa del autor ${ }^{17}$ (C.N., artículo $4^{\circ}$, inciso $1^{\circ}$ y C.P., artículo $2^{\circ 18}$ ). Es pues,

ss.; Millán Garrido, Antonio, Objeción de conciencia, pp. 10 y ss.; Moskos, Charles/Chambers, Jhon W. The new conscientious objection, pp. 3 y ss.; Navarro-Valls, Rafael/Martínez Torrón, Javier. Conflictos entre conciencia y ley, pp. 81 y ss.; Rosero Arteaga, Cristina/Tovar Ramírez, Ariadna, "La objeción de conciencia colectiva: de la ausencia al reconocimiento como derecho", pp. 7 y ss., que discurre sobre la historia de la objeción de conciencia; TAKemuRA, Hitomı, International Human Right to Conscientious objection to military service and individual duties to disobey manifestly illegal orders, pp. 1 y ss.

16 Luzon Peña, Diego Manuel. Derecho penal, Parte general, pp. 854 y ss.

17 Araujo Cuauro, Juan Carlos. “Transfusiones y testigos de Jehová. Derecho a la vida, a la libertad religiosa o de conciencia", pp. 181 y ss.

18 C.N., artículo 4: "La Constitución es norma de normas. En todo caso de incompatibilidad entre la Constitución y la ley u otra norma jurídica, se aplicarán las disposiciones constitucionales". C.P., artículo 2: "Las normas y postulados que sobre derechos humanos se encuentren consignados en la Constitución Política, en los tratados y convenios internacionales ratificados por Colombia, harán parte integral de este Código" (Negrillas por fuera del texto original). En el primer caso, 
en este segundo contexto, en el que la ley ha dispuesto la garantía a la objeción de conciencia, advirtiendo de paso que no se pueden confundir ambas hipótesis (positivas y negativas), pues tienen alcances y efectos jurídicos diferentes.

\section{Aspectos sustantivos de la objeción de conciencia: definición y desa-} rrollo. La objeción o reserva de conciencia es una garantía constitucional vinculada al ejercicio legítimo del derecho fundamental a la libertad de pensamiento, conciencia y religión, que se manifiesta, en sentido estricto, como el derecho de las personas para omitir el cumplimiento de un imperativo constitucional, legal, administrativo, contractual y judicial ${ }^{19}$, a ellas exigible (en materia de educación, salud, deberes judiciales, obligaciones laborales, jurídico-penales, etc. $\left.{ }^{20}\right)$, invocando que este deber vulnera de manera grave la autodeterminación moral del objetor, su pensamiento político o filosófico, o sus más profundas y arraigadas creencias o convicciones religiosas ${ }^{21}$.

la Corte Constitucional afirma, en la Sentencia SU-108 de 2016, que "El derecho a la objeción de conciencia es una consecuencia de la concreción del postulado de la supremacía de la Constitución y de los derechos fundamentales, como límite al poder legislativo y del respeto a las minorías".

19 Así lo afirman: JaVieR, Juvenal M., "La objeción de conciencia. Su régimen jurídico vigente en Uruguay, con especial referencia a su ejercicio por los funcionarios públicos", p. 193; Jerez Delgado, Carmen/ Madero Jiménez, Maria Victoria, "Objeción de conciencia y equilibrio", pp. 163 y ss.; Elizari, Javier, "Panorámica de la objeción de conciencia", p. 457.

20 Elizari, Javier, "Panorámica de la objeción de conciencia", pp. 490 y ss.; Javier, Juvenal. M, "La objeción de conciencia. Su régimen jurídico vigente en Uruguay, con especial referencia a su ejercicio por los funcionarios públicos", pp. 199 y ss.

21 En la Sentencia C-274 de 2016, se señala: “De manera general, ha precisado esta Corte que 'la objeción de conciencia se presenta cuando el cumplimiento de la normatividad vigente exige por parte de las personas obligadas a cumplirla un comportamiento que su conciencia prohíbe (...) Quien ejerce la objeción de conciencia (...) Es una persona que 'se apega al derecho, pero su observancia le provoca problemas con sus convicciones morales más íntimas, con su conciencia crítica'. La idea central consiste en que se incumple un deber jurídico unas razones morales y se busca con ello preservar la propia integridad moral, lo que no supone el propósito de que otras personas 'Si adhieran a las creencias un practiquen las actuaciones del objetor' ".

Existen innumerables definiciones sobre la objeción de conciencia, por ejemplo, en: JeRICó OJeR, Leticia. El conflicto de conciencia ante el derecho penal, pp. 86 y ss.; Medina Castellano, "Objeción de conciencia sanitaria en España: Naturaleza y ejercicio", p. 202, la define como "[...] el incumplimiento de un deber jurídico, pacífica y moralmente motivado, que procura salvaguardar la propia integridad moral frente a un imperativo heterónomo que se juzga injusto. En otras palabras, se trata de la negativa a obedecer una norma jurídica debido a la existencia de otro imperativo en la conciencia contrario al comportamiento pretendido por la norma, pero que en modo alguno supone un empeño de que los demás se adhieran a las creencias o imiten la conducta del objetor"; Luzón Peña, Diego Manuel, Derecho penal, Parte general, pp. 677 y ss.; Miguel Beriain, Iñigo. "La objeción de conciencia del farmacéutico: una mirada crítica", pp. 175 y ss., Navarro-Valls, Rafael /Martínez Torrón, Javier, Conflictos entre conciencia y ley, pp. 34 y ss.; Rawls, John. Teoría de la Justicia, pp. 335 y ss.; 
Parece innegable que se trata de una expresión autónoma, privada e individual que busca garantizar las diferencias, la integridad y la indemnidad del fuero interno (código de principios) de las personas naturales que, por lo demás, goza prima facie de una presunción de corrección moral frente al sentido del deber de la mayoría y del Estado, a pesar de la aparente neutralidad ética del último ${ }^{22}$.

Así las cosas, es evidente que esta institución expresa una tensión constitucional relevante entre la libertad y la conciencia (normas morales) ${ }^{23}$, y la exigibilidad al autor por la omisión de prestaciones jurídicas (físicas o económicas, públicas 0 privadas), que afectan su libertad personal y su orden de valores. Y ello la distingue de las actuaciones basadas en opciones de conciencia, en las cuales el autor tiene la alternativa de escoger entre posibles acciones de cumplimiento del deber, ante un dictamen negativo de conciencia ${ }^{24}$. Así lo reconoció la sentencia C-728 de 2009, que literalmente señala lo siguiente:

En el caso de la opción de conciencia, [...], se está ante una situación personal, que obedece al fuero interno del objetor. De este modo, subsiste la obligación general, pero la persona, por consideraciones de conciencia, puede oponerse a cumplirla. La regulación de este fenómeno, entonces, debe ser distinta, puesto que ya no se trata de identificar grupos de personas que por sus características objetivas comunes deban ser eximidas del servicio, sino que la misma debe orientarse establecer criterios para determinar la naturaleza de la objeción, su seriedad o, en general, las condiciones en las que puede tenerse como válida (Subrayado por fuera del texto original).

Ahora bien, en el moderno Derecho penal esta tensión resulta explicable con base en dos pilares fundamentales. Por una parte, el interés del Estado en ejercer

Roxin, Claus. Strafrecht, pp. 1006-1007; Valderrama Sandoval, Antonieta/López Barreda, Rodrigo, "Conciencia moral: ampliando su aplicación en salud. Aspectos teóricos y prácticos de los juicios de conciencia en Chile", p. 180 y ss.

22 Sobre este concepto: Navarro-Valls, Rafael/Martínez Torrón, Javier, Conflictos entre conciencia y ley, p. 71.

23 Castrelón Pérez, Mariana. "La objeción de conciencia al servicio militar en Colombia: análisis de la sentencia C-728 de 2009 y de sus defectos frente a los objetores de conciencia", p. 18, señala "en suma, objetar un mandato jurídico por razones de conciencia implica el ejercicio autónomo, íntimo e individual sobre lo que cada quien considera correcto e incorrecto. Sin embargo, es necesario reconocer que el ejercicio de este derecho genera una tensión entre el deber general de cumplir de norma y el mandato de la conciencia que indica que es incorrecto cumplir dicha norma". Sobre la afectación a la exigibilidad normativa: JeRICó OJER, LETICIA, El conflicto de conciencia ante el derecho penal, pp. 397 y ss.; Welzel, Hans. Derecho penal, pp. 217-218; id., El nuevo sistema del derecho penal: una introducción a la doctrina de la acción finalista, pp. 197-198.

24 Martín Sánchez, Isidoro. “Objeción de conciencia y educación para la ciudadanía”, p. 213. 
un control social penal formal e institucional, mediante imperativos que cumplan los ciudadanos para proteger los bienes jurídicos tutelados. Por otra, la capacidad del objetor, en cada caso concreto, de motivarse a cumplir con tales dictados legales 0 constitucionales (mayoritariamente legítimos) y la correlativa exigibilidad normativa para ajustar sus comportamientos a 'la norma positiva que estatuye la obligación'25.

De esta manera, la objeción de conciencia en realidad supone discutir el desvalor personal del autor en relación con el injusto realizado, con base en las creencias o convicciones personales y éticas sobre lo bueno y lo malo, que naturalmente no tienen por qué coincidir con los valores sociales mayoritarios ${ }^{26}$; creencias que le dificultan o le disminuyen al sujeto la posibilidad de motivarse en contra de la realización del delito y cumplir así con la norma jurídica, tal y como lo exige el Estado.

Dicho en otras palabras, la conciencia del autor se estructura por una serie de normas y modelos morales que le resultan estimables, deseables y prescriptivos, pues orientan sus acciones dentro de una determinada concepción social objetiva. Tales modelos de comportamiento contradicen excepcionalmente el sentido, el valor y la legitimidad de ciertas prohibiciones o mandatos a través de los cuales el Estado pretende motivarlo como ciudadano, con el propósito último de proteger los bienes jurídicos tutelados en el Código Penal.

Conviene recordar con Luzón Peña, que los casos de presión motivacional se presentan cuando haya sido "[.. .] suprimida o gravísimamente coartada la posibilidad de determinarse o motivarse por la norma jurídica ante la presión insalvable de la norma ética individual de su conciencia"27. Estas relaciones paradójicas implican, entonces, una ruptura comunicativa entre el colectivo social y el individuo, quien

25 Navarro-Valls, Rafael /Martínez Torrón, Javier, Conflictos entre conciencia y ley, p. 38; Velásquez Velásquez, Fernando. Fundamentos, p. 526. Según la Corte Constitucional, Sentencia SU-108 de 2016, el fundamento de la objeción de conciencia reside "[...] en la coexistencia de las creencias morales de cada quien y se funda en la idea de la libertad humana como principio fundamental de la ética contemporánea. En estos términos, se concibe al hombre como sujeto moral, capaz de emitir un juicio sobre un determinado comportamiento. Por ello, la libertad de conciencia incluye la facultad de emitir juicios morales internos y de actuar conforme a ellos".

26 Velásquez Velásouez, Fernando. Fundamentos, p. 549, señala que “[...] igual tratamiento deben recibir algunos casos excepcionales derivados de conductas desplegadas por los llamados autores por motivos de conciencia (religiosos, morales, o políticos), esto es, aquellas personas que realizan un injusto movido por una convicción en todo caso contraria a los valores dominantes que inspiran las normas jurídicas [...]. Como es obvio, ante un texto constitucional tan avanzado en este punto, el derecho penal no puede caminar en contravía y, si se quiere respetar los postulados del Estado social y democrático de derecho (Constitución política, artículo $1^{\circ}$ ), no tiene otra opción que la de reconocer la ausencia de culpabilidad de los autores por conciencia [...]".

27 Luzón Peña, Diego Manuel, Derecho penal, Parte general, p. 852. 
finalmente no puede adaptar a su entorno social los imperativos mayoritarios impuestos en el caso y ajustar su comportamiento al derecho. La norma primaria le resulta inexigible.

En ningún caso se trata de cuestionar la validez o vigencia general de las normas jurídicas 0 de modificarlas ${ }^{28}$, pues, como lo ha señalado ampliamente la Corte Constitucional, la objeción de conciencia no es una "evasión al ordenamiento" jurídico ni un derecho general a la desobediencia. Tampoco se busca que los demás ciudadanos sigan el ejemplo del objetor.

La conclusión en este ámbito parece evidente: en primer lugar, que la norma jurídica objetada no resulta idónea para evitar la infracción jurídica individual, pues, debido a las convicciones del autor, esta no puede ser adecuadamente interiorizada por este como un parámetro válido o como un patrón de comportamiento deseable ${ }^{29}$. Sobre este aspecto, WelzEL advierte que:

28 Didier, Maria Marta. "El derecho a la objeción de conciencia: criterios para su interpretación", p. 257; JaVIER, Juvenal M., "La objeción de conciencia. Su régimen jurídico vigente en Uruguay, con especial referencia a su ejercicio por los funcionarios públicos", p. 196; Llano Escobar, Alfonso, Objeción de conciencia institucional, pp. 27 y 28. La Corte Constitucional, Sentencia, SU-108 de 2016, dice que: "El reconocimiento a la objeción de conciencia se encuentra intrínsecamente relacionado con el derecho a la libertad de conciencia y no se constituye en una evasión al ordenamiento jurídico, sino que, por el contrario, toda sociedad democrática debe estar interesada en el respeto de los derechos individuales de cada uno de los ciudadanos. No se trata de hacer prevalecer el interés de uno o unos pocos frente a muchos o la inmensa mayoría. Es un problema de calidad democrática y respeto a los derechos individuales básicos: cuando el Estado admite la objeción de conciencia de un particular, está potenciando en beneficio de toda la sociedad ese valor fundamental".

29 Mir Puig, Santiago. Derecho Penal, Parte General, pp. 550 y 551, cuando señala que "Este es el caso del llamado "delincuente por convicción», que, generalmente por motivos religiosos o políticos, no experimenta sentimiento de culpabilidad pese a conocer el significado jurídico de su hecho. La imputación personal jurídico-penal no requiere, pues, un sentimiento ético ni psicológico, no es culpabilidad de conciencia. Si no es suficiente una culpabilidad moral sin imputación jurídicopenal, sí es bastante la imputación jurídico-penal, aunque no vaya acompañada del sentimiento de culpabilidad moral. De ahí que no deba confundirse el conocimiento de la antijuridicidad, necesario para la imputación personal, con la creencia del sujeto de que su conducta no merece ser antijurídica"; con un punto de partida similar, Muñoz Conde, Francisco/García Arán, Mercedes. Derecho Penal, Parte General, p. 421, señala que "Esta discrepancia se debe a veces a conflictos de conciencia: el sujeto tiene una actitud valorativa diferente a la de la norma que infringe $y$, aunque conoce el ámbito prohibitivo de la misma, no le reconoce eficacia motivadora de sus actos, salvo el de la simple conminación penal". Ibíd., p. 381, advierte que "La norma penal se dirige a individuos capaces de motivarse en su comportamiento por los mandatos normativos. Lo importante no es que el individuo pueda elegir entre varios haceres posibles, lo importante es que la norma penal le motiva con sus mandatos y prohibiciones para que se abstenga de realizar uno de esos varios haceres posibles que es precisamente el que la norma prohíbe con la amenaza de una pena". 
[...] cuanto más intente el Derecho, con ayuda de su sistema de sanciones, imponer una determinada concepción del mundo, tanto más entrará en conflicto con la conciencia individual. Y viceversa, cuando más se limite a los elementos fundamentales de las instituciones sociales, tanto más podrá esperar la obediencia de aquellos que tienen una convicción diferente, porque ninguna vida social es posible sin una determinada conformación institucional. Pero cuando el derecho -también dentro de estos marcos de amplias concepciones del mundo - entra en conflicto con la conciencia individual, no puede reconocer allí rectitud, pero sí debe al menos reconocer el carácter de conciencia de la auténtica decisión de conciencia contraria. La conservación de un orden supraindividual y la protección de los otros miembros de la comunidad jurídica que confía en este orden, requiere que su validez no dependa de la aprobación de la conciencia de cada individuo. En cambio, en la conformación de las consecuencias jurídicas deberá respetarse el carácter de conciencia de decisiones diferentes. Aquí precisamente tiene que mostrarse como derecho, y no imponerse simplemente como poder ${ }^{30}$.

En segundo lugar, la objeción de conciencia no implica necesariamente lo solo de manera subsidiaria) un conocimiento diferencial de ilícito (error de prohibición directo: C.P., artículo 32, numeral 11), ni una motivación anormal (inimputabilidad: C.P., artículo 33), pues la objeción es la expresión de una carga afectiva paralela o de una contra motivación valorativa, que le permite al objetor reforzar su propia identidad y autodeterminación moral, en contraposición al mandato mayoritario (desobediencia a lo normal). En todo caso, hay que advertir que la equiparación entre la objeción de conciencia y el error de prohibición es común en la doctrina ${ }^{31}$.

En términos teleológicos, también es posible señalar que la pena, en los supuestos legítimos de objeción de conciencia que no impliquen riesgos razonables de reiteración, no cumpliría con la finalidad de integrar los individuos al ordenamiento jurídico (prevención general positiva), pues se trataría de casos tan excepcionales en el marco de la vigencia de las normas, que su sanción más bien ampliaría el sentido de injusticia del castigo penal y convertiría la pena en un instrumento de sometimiento social de un individuo diverso que no se puede conducir a conciencia, según el sentido social de la norma penal. En el último caso se estaría frente a sanciones de naturaleza personalista ${ }^{32}$, que realmente pretenden imponerle al

30 Welzel, Hans, Estudios de filosofía del derecho y derecho penal, pp. 133 y 134.

31 Cabezas Salmerón, Jord. La culpabilidad o los átomos resultante de condicionamiento socioculturales, p. 42.

32 Ángel Cabo, Natalia. "El concepto de libertad y el libre desarrollo de la personalidad", p. 245, advierte que "Las medidas perfeccionistas son aquellas que, a través de instrumentos coactivos, como sanciones penales, imponen a las personas determinados modelos de virtud o de excelencia humana. Este tipo de medidas no son admisibles en un Estado constitucional que reconoce la autonomía de la persona y el pluralismo en todos los campos". 
individuo una determinada concepción moral de la sociedad (la más aceptada por todos), con base en una pena que exige simbólicamente un consenso social forzado, sobre la base de una integración social que en el caso resulta imposible, debido a la diversidad de culturas vigentes en la sociedad ${ }^{33}$.

Finalmente, hay que añadir que la falta de reconocimiento arbitrario de la objeción de conciencia (de la regla subjetiva de moralidad), como causal de inculpabilidad, podría dar lugar a la práctica de discriminaciones contra los objetores por razones de sus creencias y convicciones religiosas, políticas, filosóficas, éticas y morales, etc. ${ }^{34}$.

\section{La conciencia en el marco legal de la teoría del delito colombiana. Elementos y requisitos de la objeción de conciencia}

1. Conciencia y responsabilidad. El ejercicio de la objeción de conciencia ante la omisión de mandatos constitucionales o legales puede revestir dos formas de exclusión de la responsabilidad penal en Colombia.

En primer lugar, puede tratarse de comportamientos omisivos realizados por motivos de conciencia (secundum legem), que están debidamente previstos en la Constitución o en la ley, de manera que usualmente no pueden ser imputados objetivamente a un autor, bien porque el riesgo que se crea no es jurídicamente desaprobado, o bien porque este resulta insignificante 0 es socialmente adecuado, siendo entonces ajustados a derecho ${ }^{35}$.

Así, es motivo de especial consideración la sentencia C-274 de 2016, que declaró exequible el derecho a la objeción de conciencia por motivos morales 0 éticos, al personal de enfermería que considere su participación en procedimientos médicos dañinos como un acto contrario a sus convicciones personales. Se trata de un derecho subjetivo previsto en el parágrafo del artículo 9 de la ley 911 de

33 Jakobs, Günther. Derecho Penal, p. 702, afirma que "El derecho no puede renunciar al principio de comportamiento conforme a convicciones, ya que sin un firme contenido de normas "internas" de los sujetos es imposible una integración social fiable. [...] Si el derecho no puede renunciar a que los destinatarios de la norma desarrollen convicciones, puede también tolerar el riesgo de que ese desarrollo produzca a veces resultados perturbadores"; Roxin, CLaus, Derecho Penal, p. 952; Roxin, Claus, Strafrecht, p. 1016.

34 Didier Maria Marta, "El derecho a la objeción de conciencia: criterios para su interpretación", p. 273, señala que: "Con fundamento en lo expuesto, puede concluirse que cuando se deniega injustificadamente el ejercicio del derecho a la objeción de conciencia por razones religiosas, no solo se está violentando el mencionado derecho fundamental, sino que también se vulnera el derecho a no ser discriminado por razón de la religión".

35 Velásquez Velásquez, Fernando, Fundamentos, p. 526; Roxin, Claus, Strafrecht, pp. 120 y ss. 
2004 (parcialmente declarado inexequible). Como es evidente, en estos casos la exclusión no opera de manera automática, siendo necesario verificar la existencia de una prestación alterna del deber omitido.

Del mismo modo, la Sentencia T-823 de 2002 estudia el caso de un grupo de profesionales que, por razones de conciencia, objetaron el deber de prestar un servicio contractual de salud, toda vez que el procedimiento no cumplía los requerimientos de seguridad previstos en la lex artis, esto es, se trataba de una operación en la cual el paciente, por razones religiosas, no permitió realizar las transfusiones de sangre correspondientes en caso de ser necesarias por motivos médicos ${ }^{36}$.

En segundo lugar, se advierte la objeción de conciencia subjetiva (contra legem) que, como se ha dicho, fundamenta la realización de comportamientos omisivos en los que se tendría que verificar la posibilidad de aplicar una causal de inculpabilidad. En realidad, se trata de casos no regulados expresamente en la ley. Así sucede con el personal médico que objeta por consideraciones religiosas la práctica de abortos que cumplen con las indicaciones previstas en la Sentencia C-355 de $2006^{37}$ (en la medida en que se obliga a la mujer a tolerar el embarazo); siempre cuando el médico remita al paciente a otro profesional médico que esté en condiciones de realizar el procedimiento de aborto, en las mismas condiciones se seguridad e idoneidad.

También sería un evento de inexigibilidad el caso de los padres que apoyan al hijo (miembros todos de los testigos de Jehová) a no permitir la realización de una transfusión de sangre por motivos religiosos. En estos casos no es convincente el hecho de castigar a los progenitores por un delito de homicidio en comisión por omisión, cuando los padres ni siquiera han tratado de convencer a su hijo de hacerse la correspondiente transfusión sanguínea, también por motivos religiosos ${ }^{38}$.

36 Navarro-Valls, Rafael /Martínez Torrón, Javier, Conflictos entre conciencia y ley, pp. 197 y ss.; Rosero Arteaga, Cristina/Tovar Ramírez, Ariadna, "La objeción de conciencia colectiva: de la ausencia al reconocimiento como derecho", p. 14.

37 Jericó Ojer, Leticia, El conflicto de conciencia ante el derecho penal, pp. 472 y ss.; Luzón PeÑa, Diego Manuel, Derecho penal, Parte general, pp. 681 y ss.; Miguel Beriain, î̃igo, "La objeción de conciencia del farmacéutico: una mirada crítica", pp. 180 y ss. y pp. 187 y ss.; Montero Vega, Adela, "La objeción de conciencia de los profesionales y su relación con la atención en salud sexual y reproductiva de adolescentes en Santiago de Chile", pp. 198 y ss.; Montero Vega, Adela/González Araya, Electra. "La objeción de conciencia en la práctica clínica", pp. 124 y ss.; Navarro-Valls, Rafael, Martínez Torrón, Javier, Conflictos entre conciencia y ley, pp. 129 y ss.; Ruíz-Bursón, Francisco Javier. "La regulación de la objeción de conciencia en la ley orgánica 2/2010, de 2 de marzo, de salud sexual y reproductiva y de interrupción voluntaria del embarazo", pp. 178 y ss.

38 Araujo Cuauro, Juan Carlos "Transfusiones y testigos de Jehová. Derecho a la vida, a la libertad religiosa o de conciencia", pp. 180 y ss. En general: Cuello Contreras, Joaquín. El derecho penal español, p. 1149; Muñoz Conde, Francisco/ García Arán, Mercedes, Derecho Penal, Parte General, p. 424. 
De igual modo, son eventos de inexigibilidad (posiblemente disciplinaria), los casos en los que, por razones religiosas, las personas se niegan a prestar el juramento necesario para instaurar una denuncia penal o para rendir un testimonio (Corte Constitucional, Sentencia T-547 de 1993 y Sentencia C-616 de 1997), lo que no impediría verificar la realización de un delito de falsa denuncia o falso testimonio ${ }^{39}$, cuando el autor incumpla su deber de declarar la verdad.

Llegados a este punto, resulta fundamental distinguir los supuestos de los delitos omisivos determinados por objeción de conciencia, de aquellos delitos comisivos realizados por motivos de conciencia, creencias religiosas, técnicas 0 políticas ${ }^{40}$. Comportamientos que igualmente pueden ser declarados inculpables, debido a la incapacidad de determinación del autor (derecho constitucional a actuar en conciencia).

Un primer grupo serían los delitos políticos o la desobediencia civil. Las diferencias saltan a la vista ${ }^{41}$, en los delitos omisivos determinados por la objeción de conciencia, el comportamiento individual del autor es pasivo y generalmente no implica actos de violencia física 0 mora ${ }^{42}$; por el contrario, los delitos políticos generalmente suponen manifestaciones activas de violencia colectiva, pues el

Un grupo de casos más complejos e interesantes, sería aquel en el que el autor realiza un delito por motivos de conciencia para salvar un bien jurídico de mayor jerarquía, cuyo titular quiere sacrificar por íntimas convicciones morales o religiosas. Por ejemplo, los eventos en que el policía o el médico realizan un delito contra la autonomía de un sujeto que ha decidido suicidarse y es detenido y reducido, o se le fuerza a una transfusión de sangre para salvarle la vida. 0 supuestos que la doctrina suele tratar como verdaderos estados de necesidad en delitos por convicción, como en el caso del sujeto que extrae los órganos de un cadáver para salvar la vida de otro por razones ideológicas; 0 el hecho de extraer forzosamente sangre o tratar a un sujeto para salvar a otro. Molina Fernández, Fernando. Estado de Necesidad y justificación penal, iEs lícita la tortura en situaciones extremas?, pp. 63 y ss.

39 CP, artículos 435 y ss. (falsa denuncia); 441 (omisión de denuncia de particular); 442 y ss. (Falso testimonio). Posada Maya, Ricardo. "Falso testimonio y garantías fundamentales", pp. 81 y ss.

40 Roxin, Claus. Strafrecht, pp 1007 y 1008; Luzón Peña, Diego Manuel, Derecho penal, Parte general, pp. 854 y ss. Buenos ejemplos de esta posibilidad serían los casos previstos en la jurisprudencia constitucional, en los cuales el autor realiza huelgas de hambre, manifestaciones públicas de naturaleza política 0 religiosa, expresa sus opiniones en los medios masivos de comunicación o en las redes sociales, etc., motivados por la libertad de expresión política, ética o religiosa distintos al Cyberbullying, etc. Otros ejemplos serían aquellos que configuran ejercicios legítimos de derechos constitucionales o legales, como ocurre cuando los padres ejercen el derecho de corrección razonable por motivos de conciencia moral frente a sus hijos menores de edad. En estos casos, siempre deberá verificarse estrictamente la prevalencia de un determinado interés del menor frente a la necesidad de ejercer legítimamente el derecho de corrección. En relación con la eutanasia, v. Domínguez Márouez, Octaviano Humberto. "Objeción de conciencia, la muerte y el morir en enfermedades en etapa terminal", pp. 95 y ss.

41 Sobre estas diferencias: Rawls, John. Teoría de la Justicia, pp. 336.

42 Javier, Juvenal M, “La objeción de conciencia. Su régimen jurídico vigente en Uruguay, con especial referencia a su ejercicio por los funcionarios públicos", p. 197; RawLs, John. Teoría de la Justicia, pp. 335 y ss. 
delito exige expresamente "el alzamiento de armas"43; también suelen ser ejemplos violentos los casos de delitos causados por grupos de activistas para proteger el medio ambiente. De igual manera, mientras que la objeción de conciencia puede ser una exculpante de la responsabilidad penal, los delitos políticos (según la teoría que asuma el intérprete ${ }^{44}$ ) implican responsabilidad legal, aunque pueden ser objeto de amnistías o indultos según lo indica la Constitución ${ }^{45}$.

A su turno, la desobediencia civil (Der zivile Ungehorsam ${ }^{46}$ ) se materializa en casos en los cuales, por ejemplo, el sujeto insumiso no paga impuestos con destinación específica para hechos que él considera inmorales. Se trata usualmente de un acto “[...] público, espontáneo, de naturaleza colectiva (normalmente por minorías), no violento y de insumisión con carácter eminentemente político, a fin de ejercer una presión sobre la agenda estatal o sobre ciertas políticas públicas con el propósito de que estas sean modificadas, canceladas o cumplidas" ${ }^{\prime \prime 7}$. Ello no obsta para tener estos asuntos como casos de objeción de conciencia en sentido amplio o lato.

\section{Características y requisitos de la objeción de conciencia como causal de} inculpabilidad. La definición y los contornos de la objeción de conciencia permiten contextualizar de manera correcta sus características principales y sus requisitos, así:

\section{Características de la objeción de conciencia en la jurisprudencia constitucional}

1. El objetor de conciencia debe ser un sujeto particular o excepcionalmente un servidor público que tiene obligaciones prestacionales directas. Ello implica

43 Posada Maya, Ricardo. Aproximación al concepto jurídico del delito político, pp. 3 y ss.

44 Ibíd., pp. 14 y ss.

45 Ibíd., pp. 75 y ss.

46 Jericó Ojer, Leticia, El conflicto de conciencia ante el derecho penal, pp. 98, 258 y 259; Jerez Delgado, Carmen/ Madero Jiménez, Maria victoria. "Objeción de conciencia y equilibrio", p. 163; Medina Castellano, Carmen Dela. "Objeción de conciencia sanitaria en España: Naturaleza y ejercicio", p. 209, advierte que "Mientras que la desobediencia civil es un «acto público, no violento, consciente y político, contrario a la ley, cometido con el propósito de ocasionar un cambio en la ley o en los programas de gobierno", la objeción de conciencia carece de intencionalidad política, no busca un cambio en las leyes o programas de gobierno, sino que persigue una excepción a un imperativo jurídico concreto y actual, porque este choca con las propias convicciones morales"; Roxin, Derecho Penal, pp. 953 y 954; Roxin, Claus. Strafrecht, pp. 1017 y 1018.

47 Soto Obregón, Martha Elena/Ruiz Cañizalez, Raúl. "Tratamiento doctrinal de la objeción de conciencia y la desobediencia civil en Ronald Dworkin y Jürgen Habermas", p. 153. Otros autores: ElizARI, JaVIER. "Panorámica de la objeción de conciencia", p. 458; Navarro-Valls, Rafael/Martínez Torrón, Javier, Conflictos entre conciencia y ley, p. 35; Ruíz-Bursón, Francisco Javier. "La regulación de la objeción de conciencia en la ley orgánica 2/2010, de 2 de marzo, de salud sexual y reproductiva y de interrupción voluntaria del embarazo", pp. 166 y 167. 
reiterar que la responsabilidad penal es diferente si se trata de particulares 0 de servidores públicos. En esta dirección, el artículo $6^{\circ}$ de la C.N. plantea que los particulares pueden hacer todo lo que quieran, salvo que su comportamiento esté expresamente prohibido o mandado por la ley; mientras que los servidores públicos solo pueden hacer aquello que les permite la ley 0 , en el caso concreto, aquello que es mandado por la ley ${ }^{48}$.

De igual manera, las sentencias C-355 de 2006 y la T-388 de 2009 de la Corte Constitucional excluyeron la posibilidad de que los jueces (en ejercicio de sus funciones constitucionales) hagan uso de la objeción de conciencia, en los casos en que deban ampararle a una mujer la facultad para que le sea practicada una Interrupción Voluntaria del Embarazo (IVE).

Esta postura fue reiterada en la sentencia T-388 de 2009 y en el A327 de 2010, en el cual se advierte que "Las autoridades judiciales no pueden alegar la objeción de conciencia para abstenerse de autorizar solicitudes de interrupción voluntaria del embarazo cuando la mujer gestante se halle en los supuestos permitidos por las sentencias C-355 de 2006 y T-388 de 2009, como lo hizo el juez de primera instancia. Señaló que no existe dentro del ordenamiento jurídico colombiano una disposición que permita a las autoridades judiciales declararse impedidas -como inicialmente alegó el a quo- para abstenerse de tramitar tutelas en esas eventualidades. De una parte, indicó, los funcionarios y los funcionarios judiciales emiten sus sentencias en derecho y no en conciencia [...]"49. Para la Corte Constitucional, una actuación en este sentido implicaría una denegación injustificada de justicia y la ausencia de protección de los derechos fundamentales, lo que incluso podría constituir un prevaricato por omisión (C.P., artículo 414).

48 Constitución, artículos 6: "Los particulares sólo son responsables ante las autoridades por infringir la constitución y las leyes. Los servidores públicos lo son por la misma causa y por omisión 0 extralimitación en el ejercicio de sus funciones" y 121 "Ninguna autoridad del Estado podrá ejercer función es distintas de las que le atribuyen la Constitución y la ley".

49 Agrega la Sentencia T-388 de 2009 que, "Cuando un funcionario o funcionaria judicial profiere su fallo no está en uso de su libre albedrío. En estos casos el juez se encuentra ante la obligación de solucionar el problema que ante él se plantea —art. 230 de la Constitución—, con base en la Constitución y demás normas que compongan el ordenamiento jurídico aplicable. (...) Lo anterior no significa que como persona no tenga la posibilidad de ejercer sus derechos fundamentales; significa que en su labor de administrar justicia sus convicciones no lo relevan de la responsabilidad derivada de su investidura, debiendo administrar justicia con base única y exclusivamente en el derecho, pues es esa actitud la que hace que en un Estado impere la ley y no los pareceres de las autoridades públicas (...). Adicionalmente, admitir la posibilidad de objetar por motivos de conciencia la aplicación de un precepto legal determinado significa, en el caso de las autoridades jurisdiccionales, aceptar la denegación injustificada de justicia y obstaculizar de manera arbitraria el acceso a la administración de justicia" (subrayado por fuera del texto original). 
Por el contrario, la Corte Constitucional consideró que los órganos de control, como la Procuraduría General de la Nación, sí pueden hacer uso de la objeción de conciencia, a condición de que el cumplimiento de sus deberes vulnere profundamente su integridad y conciencia moral en un caso concreto. De esta manera, la Corte advierte que estos funcionarios no pueden obstaculizar la función pública, por lo que deberán apartarse del cumplimiento de sus deberes para que otros funcionarios públicos los ejecuten, una vez hayan manifestado expresamente su objeción. En suma, mientras que el funcionario no haga pública su objeción de conciencia, deberá cumplir inexcusablemente con los deberes que le impone el ordenamiento jurídico, para no obstaculizar la función pública, la justicia y los derechos fundamentales de los ciudadanos.

2. La objeción de conciencia solo puede ser planteada mediante un escrito motivado y personalizado, suscrito individualmente por personas naturales que tienen el deber concreto de realizar una prestación o un servicio. Así lo ha señalado la Corte Constitucional a partir de la sentencia C-355 de 2006, relativa a la objeción de conciencia en los casos de la IVE, que justamente puede ser ejercida por cada uno de los miembros del personal médico (no por el personal administrativo 0 de manera colectiva) que participa en el procedimient $0^{50}$.

Asimismo, recuérdese que la sentencia también reitera la prohibición de que las EPS o las IPS, públicas o privadas, laicas o confesionales, puedan ejercer la objeción de conciencia instituciona ${ }^{51} 0$ imponer obstáculos para el ejercicio de los derechos sustantivos constitucionales o legales de las mujeres. Igualmente, la Sentencia T-627 de 2012 confirma la improcedencia de la objeción de conciencia por parte de personas jurídicas o instituciones como los hospitales; pero deja abierta la posibilidad de acreditarla en otro tipo de supuestos.

3. La objeción de conciencia es, por regla general, una causal de inculpabilidad penal (o disciplinaria), que excluye la responsabilidad individual por la omisión de determinados comportamientos que el autor no pudo realizar y que en el futuro el sujeto tampoco realizará por su incapacidad para ajustar su comportamiento al derecho. En estos casos, la sanción penal lesiona de manera grave las libertades de conciencia, culto, religión y los derechos políticos ${ }^{52}$. Así lo indican Jescheck/WeIGeND:

50 Corte Constitucional, Sentencias T-209 de 2008, T-388 de 2009, T-841 de 20111 y T-627 de 2012.

51 Críticos: Llano Escobar, Alfonso, Objeción de conciencia institucional, pp. 33-39; Toller, Fernando M. "El derecho a la objeción de conciencia de las instituciones", pp. 168 y ss.

52 Con objeciones Roxin, Claus, Derecho Penal, p. 950 dice que "[...] es correcta la apreciación de que el hecho realizado por motivos de conciencia eximente de pena es un caso de exclusión de la responsabilidad (es decir, una causa de exculpación en el sentido de la terminología tradicional). 
La posibilidad de tener en cuenta decisiones adoptadas en conciencia ha sido defendida con frecuencia en los hechos omisivos. Esta tesis es correcta porque, de hecho, no puede ser defendible forzar a alguien por medio de una amenaza penal a una acción que rechaza por ser contraria a su conciencia. Al igual que en los dos casos anteriormente expuestos, el reconocimiento de la decisión adoptada en conciencia como causa de exclusión de la pena en los hechos omisivos presupone que el afectado por la omisión del autor, en cuyo beneficio se ordena la acción, también ha rechazado ésta. Puesto que la corrección interna de la decisión no puede ser verificada por el tribunal, en otro caso también debería quedar impune quien deja morir a un accidentado inconsciente por considerar el accidente un castigo de Dios, abandonándolo así a su propio destino ${ }^{53}$.

Algún sector de la doctrina considera que esta causal es asimilable al estado de necesidad exculpante (CP, artículo 32, numeral 7); sin embargo, esta posibilidad no deja de resultar cuestionable en el ordenamiento jurídico nacional, como quiera que en nuestro medio solo puede invocar la figura quien no "tenga el deber jurídico de afrontar" el peligro derivado de la colisión de bienes jurídicos, situación que justamente ocurre en estos casos, cuando el agente omite el cumplimiento de un determinado deber preexistente ${ }^{54}$.

\section{Esta causal de inculpabilidad opera, fundamentalmente, frente a delitos} omisivos $^{55}$. Los demás casos (no taxativos en la ley) en los que opera la objeción de conciencia como causal de ausencia de responsabilidad penal (C.P., artículo 32, numeral 5), suponen declarar la atipicidad del comportamiento, cuando la abstención haya sido regulada por la ley como un ejercicio del derecho de libertad de conciencia ${ }^{56}$.

Ello significa: el delincuente de conciencia no es inculpable desde perspectivas jurídico penales, pues el mismo desacata una ley que se corresponde con el orden constitucional de valores y con el principio democrático de la mayoría y que puede exigir por tanto con razón ser respetada. El mismo también puede comportarse conforme a Derecho (si bien en condiciones más dificultosas), pues el dictado de la conciencia produce una fuerte presión en la motivación, pero no determina excluyendo otras alternativas de acción, como lo hace una enfermedad mental o una neurosis obsesiva"; Roxin, Claus, Strafrecht, p. 1014. Otros autores: Cuello Contreras, Joaquín, El derecho penal español, p. 1127; JAKOBS, Derecho penal, pp. 698 y ss.

53 Jescheck, Hans Heinrich/Weigend, Thomas, Lehrbuch, pp. 505 y 506; Jescheck/Weigend, Tratado, p. 545.

54 Muñoz Conde, Francisco/ García Arán, Mercedes, Derecho Penal, Parte General, p. 423, sostiene que la fundamentación de la objeción de conciencia puede ser el Estado de necesidad (conflicto entre la libertad de conciencia y el deber de cumplimiento de la prestación social sustitutoria). En contra, Roxin, CLaus, Strafrecht, p. 1007. Recuérdese que muchos autores siguen una concepción monista del estado de necesidad, aunque la objeción de conciencia no sea admitida como una causal de justificación.

55 Luzón Peña, Diego Manuel, Derecho penal, Parte general, pp. 680. Con una posición mixta comisiva y omisiva: Jericó OJer, LetICIA, El conflicto de conciencia ante el derecho penal, pp. 219 y 229 y ss.

56 Cuello Contreras, Joaquín, El derecho penal español, p. 1149; Javier, Juvenal. M, "La objeción de conciencia. Su régimen jurídico vigente en Uruguay, con especial referencia a su ejercicio por los funcionarios públicos", p. 196; Luzón Peña, Diego Manuel, Derecho penal, Parte general, pp. 851 y ss.; 
Con todo, una de las críticas más recurrentes a la objeción de conciencia es, precisamente, que la ley no haya definido los casos puntuales en los que opera y las excepciones legales que la rodean, con base en la prevalencia del interés general sobre los intereses privados o particulares, según las exigencias de la vida en comunidad.

4. Se trata de una causal excepcional. En efecto, como lo ha señalado la doctrina nacional ${ }^{57}$, los ordenamientos jurídico-penales solo pueden admitir la objeción al cumplimiento de sus normas jurídicas en situaciones muy excepcionales, por ejemplo, en los eventos de la prestación del servicio militar obligatorio (Código Penal Militar, artículo 98, relativo a la desobediencia de reservistas).

Es conveniente destacar que, la consecuencia de permitir un incumplimiento generalizado de las normas penales implicaría que cada sujeto pudiese admitir la aplicación o validez (no la vigencia) de un determinado delito, con consecuencias político-criminales y dogmáticas devastadoras para la integración social y la protección de los bienes jurídicos tutelados por el ordenamiento jurídico. En otras palabras, las personas podrían determinar selectivamente qué clase de normas les resultan aplicables o no en un determinado caso, según su proyecto de vida, lo que desestructuraría la vigencia General de la ley y, por consiguiente, la garantía de jurisdiccionalidad en la solución de las controversias sociales ${ }^{58}$.

\section{Elementos dogmáticos de la objeción de conciencia, como causal innominada de inculpabilidad en el C.P. de 2000}

Ahora bien, teniendo en cuenta doctrina y la jurisprudencia de la Corte Constitucional, es posible afirmar que, para poder reconocer la objeción de conciencia como una causal de inculpabilidad, resulta imprescindible que el objetor sea un

Muñoz Conde, Francisco/ García Arán, Mercedes, Derecho Penal, Parte General, pp. 423 y 424, afirma que, "En todo caso, debe tenerse en cuenta que, cuando el sujeto no tiene obligación de actuar, por ejemplo, carece de posición de garante, su actuación no llega ni siquiera al ámbito de la tipicidad".

57 Castrelón Pérez, Mariana "La objeción de conciencia al servicio militar en Colombia: análisis de la sentencia C-728 de 2009 y de sus defectos frente a los objetores de conciencia", p. 19.

58 Corte Constitucional, Sentencia C-728 de 2009, indica que "Se trata de comportamientos que se imponen a los particulares en consideración de intereses generales de la comunidad y que responden el criterio conforme al cual todas las personas están obligadas a contribuir al mantenimiento de las condiciones que permiten la armónica convivencia. Los deberes encuentran fundamento en el principio de solidaridad y son presupuesto del orden y la existencia misma de la sociedad y del derecho. En la base de sus deberes está la idea misma de sometimiento al derecho y la obligatoriedad de las que sean revestidos obedece a la consideración de que si cada persona pudiese, según los dictados de su conciencia, decidir cuáles normas acata y cuáles no, se desvertebraría el orden y sería imposible la existencia de la comunidad organizada". 
sujeto particular (natural, no institucional) o excepcionalmente un servidor público que tiene obligaciones prestacionales directas y no obstaculiza la función pública. Un sujeto que, al existir un mandato legal o constitucional vigente y válido, declara mediante un escrito (individual, confidencial y motivado) la existencia de profundas (serias, fijas y sinceras) convicciones ideológicas, religiosas o morales que generan una contradicción insalvable entre la ley y su moral, y determinan efectivamente el incumplimiento del deber legal. Huelga manifestar que las razones de conciencia del autor deben ser demostradas plenamente a través de manifestaciones externas. Sin embargo, cuando la objeción de conciencia pueda afectar los bienes jurídicos personalísimos de terceros o los derechos colectivos, se deberá cumplir con un test de proporcionalidad entre estos derechos y los deberes, lo que puede implicar finalmente la posibilidad de exigir la realización de una prestación social alterna al deber, que garantice los derechos de terceros. Con fundamento en las características constitucionales enunciadas, véanse a continuación los elementos que permitirían configurar la objeción de conciencia:

1. Debe existir un mandato legal o constitucional de naturaleza jurídica, profesional o asistencial, que además sea concreto, claro, expreso y exigible al objetor de conciencia (CP, artículo 10), entendido éste como una persona natural. Como es apenas lógico, el deber debe ser de aquellos que el ordenamiento jurídico permite exceptuar, mientras que el deber moral al que se contrapone debe ser inexcusable ${ }^{59}$. De este modo, en principio, el Estado o las instituciones públicas 0 privadas no pueden objetar conciencia. Tampoco se reconoce el derecho cuando el objetor sea una autoridad judicial en ejercicio de sus funciones públicas.

2. La objeción de conciencia se basa en una convicción ideológica, religiosa o moral profunda, motivada y esencial, que favorece la omisión total o parcial de un comportamiento, procedimiento, tratamiento 0 acto debido que, para el caso, la ley considera delictiva. La profundidad de la motivación individual exige que esta sea más profunda que una simple opinión o una consideración colectiva. Así mismo, dicha motivación "debe obedecer a criterios objetivos susceptibles de verificación, que expliquen o justifiquen la convicción personal del objetor"60.

3. Tratándose de funcionarios públicos habilitados para ejercer el derecho a la objeción de conciencia (distintos a los funcionarios judiciales en ejercicio de sus funciones), es necesario que estos no obstaculicen la función pública, sino

59 JeRicó OJeR, Leticia, El conflicto de conciencia ante el derecho penal, p. 156. En cuanto a la relevancia de la tensión, pp. 172 y ss. y 260.

60 Corte Constitucional, Sentencia SU-108 de 2016. 
que, una vez manifestada la resistencia moral, se aparten del cumplimiento de sus deberes constitucionales o legales, para que estos deberes sean realizados por otros funcionarios públicos que garanticen de manera adecuada e idónea los derechos de los ciudadanos de acuerdo con el interés general.

4. La objeción de conciencia debe ser seria y real (C-728 de 2009 y SU-108 de 2016). La Corte Constitucional ha puesto como ejemplo de seriedad, el hecho de que el objetor vincule el incumplimiento de un determinado deber normativo, por ejemplo, con el significado irrenunciable de la libertad religiosa (Sentencias C-274 de 2016, C-728 de 2009 y T-026 de 2005), en el marco de un sistema de pensamiento coherente.

5. La objeción de conciencia debe ser profunda, fija y sincera. En otras palabras, las razones de conciencia deben ser de una entidad tal, que su falta de reconocimiento ponga en peligro o lesione los derechos a la libertad religiosa y de conciencia, como derechos fundamentales previstos en la Constitución de 1991.

Según la Corte Constitucional, la profundidad excluye creencias o convicciones superficiales al exigir que estas formen parte integral de la vida de la persona y condicionen su toma de decisiones. Por convicciones fijas se entienden aquellas que no resultan modificadas de manera fácil y tienen vocación de permanencia en el carácter del sujeto. Finalmente, la objeción de conciencia debe ser sincera ${ }^{61}$, esto es, las razones religiosas, éticas, morales o filosóficas no pueden ser pretextos utilizados de manera estratégica, falsa, 0 violenta.

En cualquier caso, la doctrina ${ }^{62}$ y la jurisprudencia Constitucional han aclarado, mediante Sentencias C-274 de 2016, C-728 de 2009 y T-388 de 2009, entre otras, que esta garantía constitucional impide hacer consideraciones sobre la justicia 0 corrección de las "razones de conciencia", ni verificar si esta se inscribe en el esquema de una determinada moral objetiva o social. Según la Corte, la sola posibilidad de que exista este debate daría lugar a conceder la objeción de conciencia63.

6. La objeción de conciencia deben ser: a) rogada mediante un escrito individual, confidencial y motivado que señale las razones por las cuales se rechaza cumplir el deber (carga de justificación); y b) demostrada suficientemente a través de manifestaciones externas. En este sentido, la Sentencia C-728 de 2009 sostiene que "en los casos en los que las convicciones o las creencias estén limitadas al fuero

61 Jericó OJer, Leticia, El conflicto de conciencia ante el derecho penal, pp. 197 y ss.

62 Ibíd., pp. 188, 194 y 261 y ss.; Roxin, Claus, Strafrecht, p. 1008.

63 En el mismo sentido, v. Muñoz Conde, Francisco/ García Arán, Mercedes, Derecho Penal, Parte General, p. 421. 
interno de la persona, es decir, que no se hayan exteriorizado de forma clara, no existe "un deber constitucional de garantizar el derecho a no ser obligado a actuar en contra de su conciencia". Ahora bien, si se trata de servidores públicos, mientras estos no expresen la objeción de conciencia, tienen la obligación inexcusable de cumplir con sus deberes constitucionales y legales.

En ningún caso se podrá negar la objeción de conciencia con base en la ausencia de regulación legal expresa porque, como lo ha señalado la doctrina, esta facultad no está sujeta a la "interpositio legislatoris"64. Sobre este último aspecto, tiene razón Estrada Vélez al afirmar que: " [... " "si la objeción de conciencia es una conquista del individuo frente al poder de las mayorías reflejado en las leyes configuradoras del ordenamiento jurídico, no tiene sentido sujetar a la potestad del diseñador de ese mismo orden el reconocimiento de una facultad, cuyo ejercicio se traduce en una excepción a la obligatoriedad de las normas por ese órgano producidas"65.

7. Debe acreditarse que las razones de conciencia del objetor hayan determinado efectivamente la omisión (propia o impropia), esto es, hayan condicionado su comportamiento delictivo (nexo de determinación) ${ }^{66}$. La Corte Constitucional, en la Sentencia C-728 de 2009, precisa que:

Debe haber un criterio de ponderación que haga énfasis en la consideración de la naturaleza del reparo de conciencia, la seriedad con la que es asumido, la afectación que su desconocimiento produce en el sujeto, etc., frente a, por otra parte, la importancia del deber jurídico en relación con la cual se plantea y las circunstancias en las que se desarrolla, aspecto en el que cabe examinar, por ejemplo, la posibilidad de suplir a los objetores en el cumplimiento del deber omitido, o de sustituirlo por otro de similar naturaleza que no planteé conflictos de conciencia. En este último sentido, la Corte Constitucional se ha pronunciado en torno a la posibilidad de conciliar el cumplimiento del deber con modalidades que lo hagan compatible con las consideraciones de conciencia.

Precisamente, con la finalidad de garantizar que la objeción de conciencia sea una figura excepcional, la doctrina exige, además, "que esa actuación en conciencia no implique peligros de repetición reiterada y por ello no resulte penalmente intolerable desde el punto de vista preventivo" ${ }^{\prime 67}$.

64 Jerez Delgado, Carmen/Madero Jiménez, Maria Victoria, "Objeción de conciencia y equilibrio", p. 168; Martín SÁnchez, Isidoro, "Objeción de conciencia y educación para la ciudadanía", p. 214; NavarroValls, Rafael/Martínez Torrón, Javier, Conflictos entre conciencia y ley, p. 42.

65 Estrada Vélez, Sergio. "iDerecho fundamental a la libertad de conciencia sin objeción? Algunos apuntes para su reconocimiento como garantía fundamental", p. 78.

66 JeRicó OJeR, Leticia, El conflicto de conciencia ante el derecho penal, pp. 262 y ss.

67 Luzón Peña, Diego Manuel, Derecho penal, Parte general, pp. 853 y ss. 
8. Respecto a sus límites, la objeción de conciencia es de dos clases: propia, cuando omite el cumplimiento de un deber jurídico (un mandato) sin afectar los derechos fundamentales de terceros o los intereses de toda la sociedad ${ }^{68}$. En este caso, la objeción de conciencia debería acreditarse de iure como una causal de ausencia de la responsabilidad penal, o directamente deberá solucionarse por otras vías jurídicas distintas a la penal69.

Por el contrario, la objeción será impropia, cuando la omisión del deber afecte derechos de terceros o contradiga deberes jurídicos vinculados al orden público, la tranquilidad, la salud pública o la seguridad colectiva. En el presente asunto, consideramos que el criterio jurídico correcto para negar lo objetable es el impacto que la objeción produzca en cada caso puntual, tanto para el objetor como para terceros.

En el caso de la exoneración de responsabilidad penal por la vulneración de bienes jurídicos personalísimos de terceros, la doctrina se muestra inflexible en aceptar la exculpante, salvo que se acredite la realización de acciones alternativas al cumplimiento del deber que garanticen tales derechos ${ }^{70}$. Sin embargo, el asunto no es así de claro cuando se analiza la vulneración de bienes jurídicos colectivos, aunque de excluirse esta posibilidad, por ejemplo, el Ministerio Público no podría negarse a participar en los procesos judiciales invocando razones de conciencia, dado que afectaría los bienes jurídicos relativos a la administración pública 0 de justicia; incluso en los eventos en los que deban garantizar simplemente los derechos de terceros sin involucrar o sacrificar su moralidad subjetiva.

No es esta la oportunidad para profundizar sobre el tema, pero en ambos casos es necesario realizar un test de proporcionalidad entre los derechos y deberes en conflicto, para verificar la prevalencia del derecho individual frente a los derechos colectivos 0 frente al derecho fundamental de terceros ${ }^{71}$. Dicho test debe tener en

68 Roxin, Claus. Strafrecht, pp. 1010 y ss.

69 Muñoz Conde, Francisco/ García Arán, Mercedes, Francisco. Derecho Penal, Parte General, p. 422.

70 Didier, Maria Marta, "El derecho a la objeción de conciencia: criterios para su interpretación", p. 268, señala que "Desde esta perspectiva, no formarían parte de la denominada "esfera material" del derecho a la objeción de conciencia aquellas acciones por las que el objetor daña o impide la realización o participación en una forma básica de bien humano, como sería el caso de quien presta su asistencia al suicidio y justifica su acción en imperativos de conciencia para eximirse de la sanción penal; 0 las prácticas de infibulación o escisión femenina, propias de ciertas comunidades islámicas, respaldadas en una determinada interpretación del Corán. Debido a que mediante dichas conductas se estaría atentando directamente contra el bien humano de la vida de quien solicita su asistencia para el suicidio, y contra el bien humano de la salud e integridad física de la mujer sobre la que se realiza dicha práctica, no cabría considerarla como un ejercicio razonable de la objeción de conciencia, encontrándose fuera del ámbito de protección del derecho bajo análisis".

71 En general: Jericó OJer, Leticia, El conflicto de conciencia ante el derecho penal, pp. 159 y 263; Mora Restrepo, Gabriel, “Objeción de conciencia e imposiciones ideológicas: el Mayflower a la deriva", p. 267. 
cuenta, según la Sentencia C-274 de 2016, dos grupos de criterios enfrentados y un componente adicional: el primer grupo exige valorar: a) la naturaleza del reparo de conciencia; b) la seriedad con la que es asumido; y c) la afectación que su desconocimiento produce a quien objeta ${ }^{72}$. A su turno, el segundo grupo de argumentos exige verificar: a) la importancia del deber jurídico frente al cual se plantea la objeción; b) su mayor o menor proyección social; y c) el grado de interferencia que la objeción produce frente a los derechos de terceras personas y el grado de reversibilidad de la lesión que tal incumplimiento produce ${ }^{73}$. Finalmente, el criterio que añade la jurisprudencia es la fungibilidad del objetor frente al cumplimiento del deber rehusado, y la posibilidad de sustituirlo por el cumplimiento de un deber similar que no genere ninguna objeción de conciencia ${ }^{74}$.

9. De conformidad con lo anterior, en la mayoría de los casos es necesario demostrar la realización de una prestación social sustitutoria al deber, que garantice plenamente los derechos fundamentales de terceros. Sucede así cuando se invoca la objeción de conciencia para la práctica de un aborto legal a una mujer por parte de un médico. En estos eventos es imprescindible para concederla que se garantice la intervención de otro profesional idóneo que esté dispuesto a practicar la IVE en iguales condiciones de calidad y de seguridad (Sentencias C-274 de 2016 y SU-108 de 2016). Todo ello, sin imponer cargas adicionales que estorben el ejercicio de los derechos o los servicios rehusados por el objetor (Sentencias C-355 de 2006, T-209 y T-946 de 2008 y T-388 de 2009, T-62 de 2012 y el A-009 de 2015).

Esta propuesta también se ha hecho en materia del servicio militar obligatorio en la Sentencia T-026 de 2005, señalando como actuación alternativa que los objetores presten un servicio social obligatorio. Pero, igualmente, en ciertos casos debería poder funcionar frente al salvamento que deban realizar los bomberos o los policías bachilleres.

10. Finalmente, subyace a todos estos requisitos la exigencia de que el sujeto haya actuado con la finalidad de objetar conciencia, de oponerse a la validez moral de una norma jurídica, y de hacer prevalecer frente a esta sus más arraigadas convicciones y creencias religiosas y morales.

72 Corte Constitucional, Sentencia C-728 de 2009.

73 Corte Constitucional, Sentencia T-388 de 2009.

74 Corte Constitucional, Sentencia C-728 de 2009 


\section{Conclusiones}

Primero. La objeción de conciencia es un derecho y una garantía fundamental reconocida por la Constitución de 1991 en el artículo 18. Esta funge como una causal de ausencia de responsabilidad, en los casos en que la omisión de un deber del autor genere responsabilidad jurídico penal, pero su cumplimiento alterno produzca una tensión insalvable entre este deber y sus íntimas convicciones y creencias ideológicas o religiosas. Como derecho Constitucional, este es permanente y de inmediato y directo cumplimiento.

Segundo. Desde el punto de vista legal, el ordenamiento jurídico distingue los eventos de objeción de conciencia de los casos de actuación basados en la conciencia, incluyendo en los últimos las hipótesis de desobediencia civil. En realidad, la objeción de conciencia opera, de manera prevalente, en los supuestos en los cuales el objetor se abstiene del cumplimiento de un mandato constitucional, legal, administrativo, judicial o contractual, invocando para ello excepcionales y graves reparos morales que le impidan actuar conforme al derecho, esto es, se permite cuestionar la validez de la norma en un caso particular. No se trata de una evasión general al ordenamiento jurídico, pues esta causal lo estabiliza a la luz del derecho a la libertad de conciencia. Por el contrario, los comportamientos basados en la conciencia son actuaciones usualmente ideologizadas, que buscan atacar la vigencia general de la norma o del ordenamiento, incluso empleando métodos violentos.

Tercero. En el ámbito penal, la objeción de conciencia puede ser tratada de dos formas. Como causal de atipicidad por ausencia de imputación objetiva, cuando la desaprobación del riesgo se ata directamente al ejercicio legítimo de derechos subjetivos (CP, artículo 32, numeral 5). Esta primera posibilidad exige que la objeción de conciencia esté expresamente regulada en términos legales o constitucionales, como sucede con la objeción de conciencia sanitaria (participación de personal de enfermería), en las hipótesis de aborto o frente al servicio militar obligatorio. Todos estos casos usualmente comportan razones de conciencia religiosa, aunque no se limitan a ellas.

Cuando la objeción no esté reglamentada penalmente, debería ser tratada como una causal de inculpabilidad (inexigibilidad). Ello se debe a que al autor le es muy difícil: a) motivarse a cumplir la norma jurídica, debido a la contradicción insalvable que produce la inexcusabilidad del cumplimiento del deber moral; y b) actuar conforme al derecho. Un ordenamiento democrático, en estos casos, encuentra intolerable la intromisión del derecho a la libertad de conciencia individual, y, por consiguiente, rescata la dignidad e identidad de la persona. 
Cuarto. Lo dicho implica afirmar que la objeción de conciencia no es una institución automática ni absoluta. Para que ella se pueda reconocer como causal de inculpabilidad, resulta imprescindible que el objetor sea un sujeto particular (natural, no institucional) o excepcionalmente un servidor público que tiene obligaciones prestacionales directas y no obstaculiza la función pública, quien, al existir un mandato legal o constitucional, declara mediante un escrito (individual, confidencial y motivado) la existencia de profundas (serias, fijas y sinceras) convicciones ideológicas, religiosas o morales que determinan efectivamente la omisión del deber. Las razones de conciencia que invoca el autor deben poder ser plenamente demostradas mediante manifestaciones externas. Así mismo, cuando la objeción de conciencia pueda afectar los bienes jurídicos personalísimos de terceros o los derechos colectivos, se deberá efectuar un test de proporcionalidad entre los derechos y deberes en conflicto, con la posibilidad de exigirle al objetor la realización de una prestación social sustitutoria al deber, que garantice plenamente los derechos fundamentales de terceros.

\section{Bibliografía}

Ángel Cabo, Natalia. "El concepto de libertad y el libre desarrollo de la personalidad", En: Constitución y democracia en movimiento, Helena Alviar, Julieta Lemaitre, Betsy Perafán (Comp.), Bogotá, Uniandes, 2016, pp. 239-258.

Ángel Ordaz, Carlos. "Non violencia, Objeción de conciencia e insumisión en España, 1970-1990", En: Polis, No. 43, 2016, en línea: http://polis.revues.org/11618 Doi: 10.4000/polis.11618, pp. 1/17.

Araujo Cuauro, Juan Carlos. "Transfusiones y testigos de Jehová. Derecho a la vida, a la libertad religiosa o de conciencia", En: Fronesis, Universidad de Zulia, vol. 22, №. 3, 2015, pp. 177-194.

Cabezas Salmerón, Jordi. La culpabilidad o los átomos resultante de condicionamiento socioculturales, Barcelona, Anthropos, 2014.

Casas Becerra, lidia/Dides Castillo, Claudia. "Objeción de conciencia y salud reproductiva en Chile: Dos casos paradigmáticos", En: Acta Bioethica, No. 13 (2), 2007, pp. 199-206.

Castrelón Pérez, Mariana. "La objeción de conciencia al servicio militar en Colombia: análisis de la sentencia C-728 de 2009 y de sus defectos frente a los objetores de conciencia", en: La objeción de conciencia como un derecho, Manuel Iturralde compilador, Bogotá, Universidad de los Andes, 2014. 
Cohn, Marjorie/Gliberd, Kathleen. Rules of disengagement, The politics and honor of military Dissent, Sausalito, PoliPoint Press, 2009.

Cuello Contreras, Joaquín. El Derecho penal español, Parte General, $3^{a}$ ed., Madrid, Dykinson, 2002.

Didier, María Marta. "El derecho a la objeción de conciencia: criterios para su interpretación", En: Dikaion, No. 24, 2, 2015, pp. 253-281. Doi: 10.5294/ DIKA.2015.24.2.3.

Domínguez Márouez, Octaviano Humberto. "Objeción de conciencia, la muerte y el morir en enfermedades en etapa terminal", En: Interfaces, Acta Bioethica, No. 15 (1), 2009, pp. 94-99.

ElizARI, Javier. "Panorámica de la objeción de conciencia", En: Moralia, No. 35, 2012, pp. 455-507.

Estrada Vélez, Sergio. "¿Derecho fundamental a la libertad de conciencia sin objeción? Algunos apuntes para su reconocimiento como garantía fundamental", En: Estudios Socio-Jurídico No. 11 (1), enero-junio de 2009, Bogotá, pp. 65-83.

Heval Çınar, Özgür/Üstercí, Coşkun. Conscientious objection, Resisting militarized society, London-New York, Zed Books Ltd, 2009.

JaVIER, Juvenal M. "La objeción de conciencia. Su régimen jurídico vigente en Uruguay, con especial referencia a su ejercicio por los funcionarios públicos", En: Revista de derecho de la Universidad de Montevideo, No. 28, Uruguay, 2015, p. 181-317.

Jerez Delgado, Carmen/Madero Jiménez, Mª Victoria. "Objeción de conciencia y equilibrio", En: Revista Jurídica de la Universidad Autónoma de Madrid (RJUAM), No. 28, Madrid, 2013-II, pp. 161-176.

Jericó OJer, Leticia. El conflicto de conciencia ante el derecho penal, Madrid, La Ley, 2007.

Jescheck, Hans HeinRich y Weigend, Thomas: Lehrbuch des Strafrechts, Allgemeiner Teil, $5^{a}$ ed., Berlin, Duncker \& Humboldt, 1996. Traducción al castellano: Tratado de Derecho Penal, Parte General, Miguel Olmedo Cardenete (trad.), 5a ed., Granada, Comares, 2002.

Laffitte, Jean. "historia de la objeción de conciencia y diferentes acepciones del concepto de tolerancia", En: Vida y ética, Año 8, No. 2, Instituto de Bioética (UCA), dic 2007, pp. 81-110.

Llano Escobar, Alfonso SJ. Objeción de conciencia institucional, Bogotá, Pontificia Universidad Javeriana- Ed. Ibáñez- Ed. Depalma, 2011. 
Londoño Lazaro, María Carmelina. "La protección internacional de la objeción de conciencia: Análisis comparado entre sistemas de derechos humanos y perspectivas en el sistema interamericano", En: Anuario colombiano de derecho internacional (ACDI), vol. 9, 2016, pp. 233-272.

Lukae de Stier, María Liliana. "Objeción de conciencia y antropología", En: Vida y ética, Año 8, No. 2, Instituto de Bioética (UCA), dic 2007, pp. 111-121.

Luzón Peña, Diego Manuel. Derecho penal, Parte general, $3^{\text {a }}$ ed., ampliada y revisada, Montevideo-Buenos Aires, BdeF, 2016.

Martín SÁnchez, Isidoro. "Objeción de conciencia y educación para la ciudadanía", En: Revista Jurídica de la Universidad Autónoma de Madrid (RJUAM), No. 19, 2009I, Madrid, pp. 211-228.

Medina Castellano, Carmen Delia. "Objeción de conciencia sanitaria en España: Naturaleza y ejercicio", En: Revista Derecho PUCP, No. 69, 2012, pp. 201-223. Miguel BeriAIN, IÑIGo. "La objeción de conciencia del farmacéutico: una mirada crítica", En: Revista de Derecho UNED, No. 6, 2010, pp. 173-198.

Millán GarRido, Antonio. Objeción de conciencia. Prestación social, Madrid, Trivium, 1992.

Molina Fernández, Fernando. Estado de Necesidad y justificación penal, ¿Es lícita la tortura en situaciones extremas?, Bogotá, Ibáñez-Santo Tomás, 2009.

Montero Vega, Adela. "La objeción de conciencia de los profesionales y su relación con la atención en salud sexual y reproductiva de adolescentes en Santiago de Chile", En: Acta Bioethica, 20 (2), 2014, pp. 197-206.

Montero Vega, Adela/González Araya, Electra. “La objeción de conciencia en la práctica clínica", En: Acta Bioethica, №. 17 (1), 2011, pp. 123-131.

Mora Restrepo, Gabriel. "Objeción de conciencia e imposiciones ideológicas: el Mayflower a la deriva", En: Estud. Socio-Juridicos, No. 13 (2), julio-diciembre 2011, Bogotá, pp. 249-273.

Morellı, Mariano. "La objeción de conciencia en el derecho", En: Vida y ética, Año 8 , No. 2, Instituto de Bioética (UCA), dic 2007, pp. 41-80.

Moskos, Charles C./Chambers, Jhon Whiteclay. The new conscientious objection, From sacred to secular resistance, New York-0xford, Oxford University Press, 1993. Muñoz Conde, Francisco/García Arán, Mercedes. Derecho penal, Parte general, ga ed., Valencia, Tirant lo Blanch, 2015.

Navarro-Valls, Rafael/Martínez Torrón, Javier. Conflictos entre conciencia y ley, Las objeciones de conciencia, 2a ed., Madrid, lustel, 2012. 
Perazzo, Gerardo. "Objeción de conciencia y administración hospitalaria", En: Vida y ética, Año 8, No. 2, Instituto de Bioética (UCA), dic 2007, pp. 191-210.

Posada Maya, Ricardo. "Aproximación al concepto jurídico del delito político", en Delito Político, Terrorismo y problemas de Derecho Penal, Ricardo Posada Maya (Coord.), Bogotá, Biblioteca Jurídica Uniandina, Facultad de Derecho, Universidad de Los Andes, 2010, pp. 3 y ss.

. "Falso testimonio y garantías fundamentales. A propósito de la

C.S.J., Sent. del 24 de junio de 2015, SP8032-2015, Rad. 39703, M.P.: Gustavo Enrique Malo Fernández", En: Estudios Críticos de la jurisprudencia de la Corte Suprema de Justicia No. 5, Ricardo Posada Maya/Fernando Velásquez Velásquez/ María Camila Correa Flórez (Editores académicos)/ et al. Colección Ciencias Penales, Ricardo Posada Maya (Dir.), Bogotá, Ed. Uniandes- Universidad Sergio Arboleda, Ed. Ibáñez, 2017, pp. 81-127.

Rawls, John. Teoría de la Justicia, 2ª ed., México, Fondo de Cultura Económica, 1995. Revello, Rubén. "La objeción de conciencia en los documentos internacionales", En: Vida y ética, Año 8, No. 2, Instituto de Bioética (UCA), dic 2007, pp. 23-31. Rosero Arteaga, Cristina/Tovar Ramírez, Ariadna. "La objeción de conciencia colectiva: de la ausencia al reconocimiento como derecho", En: Revista de derecho público No. 33, julio-diciembre, Universidad de Los Andes, Bogotá, pp. 3-24.

Roxin, Claus. Strafrecht, Allgemeiner Teil, Band I, Grundlagen, Der Aufbau der Verbrechenslehre, 4 Auf., München, Verlag, 2006. . Derecho Penal, Parte General, T. I, Diego Manuel Luzón Peña/ Miguel Díaz y García de Conlledo/Javier de Vicente Remesal (trads.), Madrid, Civitas, 1997.

Ruíz-Bursón, Francisco Javier. "La regulación de la objeción de conciencia en la ley orgánica 2/2010, de 2 de marzo, de salud sexual y reproductiva y de interrupción voluntaria del embarazo", En: Persona y Derecho, No. 63, 2010-2, pp. 163-196.

Soto Obregón, Martha Elena/Ruiz Cañizalez, Raúl. "Tratamiento doctrinal de la objeción de conciencia y la desobediencia civil en Ronald Dworkin y Jürgen Habermas", En: Opinión Jurídica, Vol. 12, No. 23, enero-junio 2013, Medellín, pp. 151-166. Takemura, Hitomi. International Human Right to Conscientious objection to military service and individual duties to disobey manifestly illegal orders, Springer, Berlin-Heidelberg, 2010.

Toller, Fernando M. "El derecho a la objeción de conciencia de las instituciones", En: Vida y ética, Año 8, No. 2, Instituto de Bioética (UCA), dic 2007, pp. 163-189. 
Valderrama Sandoval, Antonieta/López Barreda, Rodrigo. "Conciencia moral: ampliando su aplicación en salud. Aspectos teóricos y prácticos de los juicios de conciencia en Chile", En: Acta Bioethica, №. 17 (2), 2011, pp. 179-188.

Velásouez, Fernando. Fundamentos de derecho penal, Parte general, Bogotá, Ed. Andrés Morales, 2017.

Welzel, Hans. Derecho penal alemán, Parte General, 11 ed. (4ª castellana), Trad. Juan Bustos Ramírez y Sergio Yáñez, Santiago, Jurídica de Chile, 1997.

. El nuevo sistema del derecho penal, Una introducción a la doctrina de la acción finalista, Montevideo-Buenos Aires, BdeF, 2001.

Estudios de filosofía del derecho y derecho penal, MontevideoBuenos Aires, BdeF, 2006. 